\title{
A Bayesian Approach to Investigating Factors Influencing Polytechnic College Students' Academic Achievement
}

\author{
Kidane A. Getahun \\ Bahir Dar Institute of Technology, Bahir Dar University, Bahir Dar 6000, Ethiopia \\ Correspondence should be addressed to Kidane A. Getahun; alemkidtsega@gmail.com
}

Received 21 September 2021; Revised 15 December 2021; Accepted 23 December 2021; Published 6 January 2022

Academic Editor: Zhonggen yu

Copyright ( $\odot 2022$ Kidane A. Getahun. This is an open access article distributed under the Creative Commons Attribution License, which permits unrestricted use, distribution, and reproduction in any medium, provided the original work is properly cited.

\begin{abstract}
TVET plays a significant role in human resource development and, as a result, in a society's progress and prosperity. The study is aiming at identifying the key factors influencing students' academic success at polytechnic colleges. The study's target population was regular Bahir Dar Polytechnic College students in the 2019/2020 academic year. Stratified random sampling was employed to conduct a cross-sectional survey of 536 participants. The author employed SPSS version 25 and WinBUGS 1.4 for quantitative data analysis. Bayesian logistic regression was used to model the factors that significantly influence TVET students' academic achievement. Gender, age, family monthly income, study hours, stimulant use during the study, English language proficiency, EGSECE score, previous perceptions of TVET, teacher satisfaction, and field of study placement satisfaction were identified as factors that significantly influenced TVET students' academic achievements. Being female, having a low family income, studying for a shorter period, using stimulants while studying, having a low English language proficiency, having a low EGSECE result, having a negative perception of TVET, and having low satisfaction with field of study were all linked to lower academic achievement in this study. According to the findings, students should spend more time in learning and consume fewer stimulants during their studies. The Ministry of Education should modify the TVET curriculum to aid students in improving their English language skills. Teachers in TVET should also receive ongoing capacity-building training. Finally, rather than imposing norms and limits (in terms of student achievement), TVET colleges should respect students' free choice of training sector (department).
\end{abstract}

\section{Introduction}

According to the definition by [1], TVET refers to "aspects of the educational process involving, in addition to general education, the study of technologies and related sciences and the acquisition of practical skills, attitudes, understanding, and knowledge relating to occupants in various sectors of economic and social life." As stated by [2], technical and vocational education and training (TVET) is a world of education and training that prepares citizens to flexibly respond to changing technology and the labor market by bringing knowledge, attitudes, and skills across different occupations and technologies. The participants in https://unevoc.unesco.org/home/ UNESCO\&context=the meeting of international experts on technical and vocational education and training [3] agreed that, since education is considered the key to effective development strategies, technical and vocational education and training
(TVET) must be the master key that can alleviate poverty, promote peace, conserve the environment, improve the quality of life for all, and help achieve sustainable development.

Global experience has shown that the mere expansion of TVET does not solve the problems of unemployment and the low productivity of the economy. TVET must respond to the success needs of the labor market and create a competent, motivated, and adaptable workforce capable of driving economic growth and development [4]. Realizing the aforementioned national development requires a clear and robust TVET policy and strategy. In 2007, the African Union [5] drafted the Strategy to Revitalize Technical and Vocational Education and Training in Africa. The report states a new awareness among many African countries of the critical role that TVET plays in national development. The strategy aims to revitalize and modernize TVET in Africa and transform it into mainstream African youth activity. 
The objective of the 2008 National TVET Strategy of Ethiopia MoE [6] was to create a competent, motivated, adaptable, and innovative workforce in Ethiopia contributing to poverty reduction and social and economic development through facilitating demand-driven, highquality technical and vocational education and training, relevant to all sectors of the economy, at all levels, and to all people in need of skills development. The TVET program in Ethiopia is primarily supply-driven. Even though the TVET strategy stresses the importance of ensuring that TVET is flexible enough to accommodate the demand, the allocation of students to TVET institutions and the curriculum and the specialization offered are determined by the government. The 2008 National TVET Strategy contrasts market-driven TVET systems, where the demand for particular specialization and the fields of study is governed by the "invisible hand" [7]. Students have been admitted to TVET programs based mostly on their performance in the Ethiopian General Secondary Education Certificate Examination (EGSECE) after completing grade 10. TVET institutes offer school-based skill training for one year $(10+1)$ or level 3 qualifications to three years $(10+3)$ or level 5 qualifications.

Educational researches in Ethiopia mainly focus on general education. The TVET program is considered a separate program from that of general education. As [8] pointed out the need for more studies and documentation in the TVET sector of education, they stated that studies made on the technical and vocational education and training program are almost nonexistent. Documentation, research, and evaluation outputs appear to be neglected. This needs to be the concern of all stakeholders." The acute shortage of TVET related research was also recognized as one of the strategic issues during the development of the national TVET strategy. According to the Ministry of Education, TVET development is currently hampered by a severe lack of relevant data and information about TVET issues necessary to inform planning, monitoring, and evaluation in the TVET system. At the moment, TVET related research is provided mainly through international experts. Research capacities within Ethiopia are relatively underdeveloped. Therefore, high-quality domestic TVET research capacities need to be built in Ethiopia to become self-reliant in the long run.

Students' academic performance has always been a topic of interest for educators. Educators and researchers have long been interested in identifying and understanding the variables contributing to academic excellence. Many researchers have identified demographic, socioeconomic, family, and school factors as variables contributing to students' academic performance $[9,10]$.

There are currently just a few researchers looking into the relationship between students' sociodemographics, academic readiness, and school characteristics in TVET and their achievement. As a result, the goal of this research was to figure out what factors influence students' academic success in polytechnic colleges. Therefore, the author posed the following research question to conduct the investigation based on the prior assumptions: (i) What major sociodemographic, academic, and school characteristics significantly impact students' academic performance at polytechnic colleges?

\section{Literature Review}

There is no universally agreed definition of technical and vocational education and training (TVET). Questions arise as to whether it refers only to postcompulsory education and whether it encompasses work-based training. In broad terms, TVET might be defined as the wide range of courses/ skills that help to prepare for entering employment. According to [11], if education is the key to economic and social development, then TVET is the master key that opens the doors of poverty alleviation, greater equity, and justice in society. The purpose of TVET is to make people self- employable and to be a vehicle of transition for individuals to the world of work. Generally, technical and vocational education and training prepares learners for jobs based on manual or practical activities, traditionally nontheoretical, and related to a specific trade, occupation, or vocation, and hence the learner's term.

2.1. Challenges of TVET. The significance of TVET to one's nation's economy is undoubtedly vast. It is believed that teachers and trainers of TVET have trained about two-thirds of the workforce in the world. Despite such relevance [12], TVET in many countries has a low social acknowledgment, and the teachers and trainers in TVET are far from being recognized as professionals. For many parents and students, TVET remains a 'second-class' education. One reason is that TVET provides training but does not guarantee a job. These misunderstandings of vocational education by society will discourage students' interest to register in vocational colleges. Even those who enroll may do so out of curiosity and not desperation (anxiety). Studies on the situations in Ghana and Nigeria [13] have focused on the low public perception of TVET programs in many African countries, where participants were viewed as having the less intellectual ability and as generally comprising school dropouts or illiterates.

Similarly, the authors in [14] reported that many Ghanaian parents discourage their children from pursuing TVET programs due to the limited academic opportunities and lack of social prestige associated with these programs. They attributed the stigmatization of TVET in Ghana and other African countries to the centering of colonial education in the humanities and a postcolonial drive to increase the proportion of white-collar workers and intellectuals. Similarly, the authors in [15] found that Nigerian students did not pursue TVET as their first choice due to its reduced social status and prestige in their community, which family and peers reinforced. Undermining TVET education and students were existing and deep-rooted problems in Ethiopia. One indication is that TVET programs in Ethiopia are for those students who cannot join the university preparation program because of their lower EGSECE results or because they have failed to achieve the scores for admission to the preparatory program. 
2.2. Factors Influencing Academic Achievement of Students. Several factors have been identified as contributing to students' academic performance beyond the secondary (i.e., tertiary) level of education. They include self-efficiency, anxiety, stress and health, study habit and skills, social integration, academic support, one's choice of courses, attitudes, prior academic performance, student's background, motivational levels, financial support, teaching strategies, age, gender, and intellectual capabilities. A study carried out by [16] shows that gender, taken courses, prior performance, marital status, and age significantly contribute to academic performance. They also observe interactions between the student characteristics which further contribute to their academic performance. According to [17], there is a significant gradient between each parent's education level and their child's educational attainment. This is also supported by [18]. According to [19], students who missed class on a given date were significantly more likely to respond incorrectly to questions relating to material covered that day than those who were present. Moreover, various studies have found that peer influence impacts student performance [20-22] and show that peer influence has more potent effects than immediate family.

\section{Data and Methodology}

The study was conducted at Bahir Dar Polytechnic College, Ethiopia. In July 2011, it became polytechnic college. The study's participants were all Bahir Dar Polytechnic College regular students in the 2019 academic year. The current study relied heavily on primary data obtained via a selfadministered questionnaire. The questionnaire was divided into three sections: demographic variables, academic related characteristics, and questions assessing students' satisfaction with school facilities in general. A pilot study on 30 students was employed to test the reliability and validity of the questionnaire. For this investigation, a cross-sectional sample design was employed. Because the students were assigned to distinct training sectors, a stratified random sampling technique was used to choose a representative sample.

3.1. Variables of the Study. The academic achievement of TVET students is the study's dependent variable, which was gathered from the Polytechnic College's registrar's office at the end of the academic year. After reviewing related literature, sociodemographic variables such as student age, gender, training sector, department, level, batch, home location, family monthly income, parental employment status, the highest educational level in family, student's monthly income, and marital status, as well as school variables such as EGSECE result, study hours per day, study place, English language proficiency, class size, class participation, satisfaction with department placement, teaching methodology, and teachers' skill and experience, college reputation/status, and school facility, were independent variables considered in the study.
3.2. Bayesian Logistic Regression. When there are a categorical dependent variable and a mixture of continuous and categorical independent variables, logistic regression modeling is a regularly utilized tool for data analysis. This study employed Bayesian logistic regression since it produces a posterior distribution rather than a single point estimate like the standard technique (frequentist approach). Bayesian models are constructed using multiple, simultaneously running Markov chains that use priors to inform posteriors and posteriors themselves to inform newly constructed posteriors until all of the chains converge or, in layman's terms, agree on the model parameters. Because of the intensive nature and built-in flexibility of Bayesian modeling, Bayesian models end up being very precise and valuable to us.

In the Bayesian framework, three key components are needed for parameter estimation: the prior distribution, the likelihood function, and the posterior distribution. Bayesian inference starts with formulating a prior probability distribution over the unknown parameters $\beta$, which summarizes a set of beliefs of knowledge before we observe the data [23]. If $\beta$ is a random variable with probability density function $f(\beta)$ and likelihood function $f(\operatorname{data} \mid \beta)$, then, according to Bayes theorem, the posterior distribution function can be written as follows:

$$
f(\beta \mid \text { data })=\frac{f(\text { data } \mid \beta) \times f(\beta)}{f(\text { data })} \propto \text { likelihood } \times \text { prior. }
$$

This implies

$$
\begin{aligned}
f(\beta \mid y, X)= & {\left[\prod_{i=1}^{n}\left(\left(\frac{e^{Z}}{1+e^{Z}}\right)^{y_{i}}\left(1-\frac{e^{Z}}{1+e^{Z}}\right)^{1-y_{i}}\right)\right.} \\
& \left.\times \prod_{j=0}^{p} \frac{1}{\sqrt{2 \pi} \delta_{j}} \exp \left(-\frac{1}{2}\left(\frac{\beta_{j}-\mu_{j}}{\delta_{j}}\right)^{2}\right)\right],
\end{aligned}
$$

where $Z=\beta_{0}+\beta_{1} x_{i 1}+\beta_{2} x_{i 2}+\cdots+\beta_{p} x_{i p}, \beta_{0}$ is the constant term, and $\beta_{i}$ are the coefficients of predictor variables $x_{i k}$.

The Markov chain Monte Carlo (MCMC) method determined the posterior distribution. MCMC is a general method that generates the estimates of $\beta$ (unknown parameters) from appropriate distribution and then corrects the values generated better to estimate the desired posterior distribution [24]. The Gibbs sampling algorithm is a method used to generate an instance from the distribution of each variable in turn, conditional on the current values of the other variables. The term convergence of an MCMC algorithm refers to whether it has reached its equilibrium (target) distribution [25]. Several diagnostic tests have been developed to monitor the algorithm's convergence, such as time series, density, autocorrelation, and Galman Rubin [26]. WinBUGS version 1.4 was used for running the Gibbs sampling algorithm.

\section{Results}

The academic achievements of TVET students are the response variable in this study. According to data acquired from the registrar's office, $76.3 \%$ of the 536 students who 
took part in the study were deemed academically competent. Table 1 shows the sociodemographic characteristics of the participants in this study.

4.1. Sociodemographic Characteristics of Respondents. Female TVET students made up $44.4 \%$ of the study, while male TVET students made up 55.6\%. This investigation used proportional allocation to deliver the same or higher precision than a simple random sample of the same size. As a result, construction students took the largest share of the sample, accounting for $44.4 \%$, while textile and garment students took the smallest share, accounting for only $2 \%$. Approximately $78.4 \%$ of the respondents were from cities, and nearly half of them (50.4\%) lived with their families. It was also discovered that certificates and above were the family's highest educational level for approximately $32 \%$ of respondents in the study. Nearly a quarter of the students in our sample pay for their tuition fees.

The students in the research had an average age of 19.9 years, with a standard deviation of 1.9 years. In the Ethiopian General Secondary Education Certification Examination (EGSECE), students in this research got a mean grade point of 2.16 with a standard deviation of 0.22 (Table 2).

\subsection{Academic Related Characteristics of Respondents.} Table 3 presents that over half of the respondents preferred to study in a library, with $40.7 \%$ using nothing, $26.1 \%$ using gum, $21.6 \%$ using coffee, and $11.6 \%$ using Khat as a stimulant when studying. One-third of the respondents had low command of English, compared to $40.7 \%$ who had a good command of English and $26.7 \%$ who had a very good command of English. Full-time employment was held by $38.2 \%$ of the respondents. About $16 \%$ of the 536 students understudy had little understanding about TVET, 55\% had medium awareness, and the remaining 28.9\% showed high awareness. According to respondents, lack of choice (36.9\%) or TVET benefits $(25.9 \%)$, such as low tuition prices, future job chances, or fear of general education, are the main reasons for enrolling. Around $90 \%$ of students believe that they will have a job following graduation.

4.3. Satisfaction of Respondents on Overall School Facilities. The survey also employed a 5-point Likert scale to measure student satisfaction with school facilities. Table 4 shows the frequency and percentages of variables assessing TVET students' satisfaction with library service, instructional facilities, teaching approaches, teachers, class environment, college reputation, and department placement.

4.4. Bayesian Logistic Regression Analysis. Variable selection was made using univariate analysis of each predictor with the response. The Bayesian logistic regression model was built using variables with a degree of significance of less than 0.25 . As a result of the univariate analysis, 16 variables were discovered. The prior distributions for all parameters were assumed to be normally distributed with mean zero and variance 1000 in the current study. It is known that the results of Bayesian logistic regression analysis are valid after convergence is assured. This analysis used the time series plots, Gelman Rubin statistics, autocorrelation plots, and density plots to check convergence. According to convergence diagnostics examined, the chains converge to a stationary distribution; thus, the last 24,000 iterations can be used to infer the posterior distribution parameters.

One way to assess the accuracy of the posterior estimates is by calculating the Monte Carlo error for each parameter. The Monte Carlo error (MC error) estimates the difference between the mean of the sampled values (i.e., an estimate of the posterior mean for each parameter) and the true posterior mean. The simulation should be run as a rule of thumb until the Monte Carlo error for each parameter of interest is less than $5 \%$ of the sample standard deviation. The Monte Carlo error (MC error) and sample standard deviation (Sd) are presented in the summary statistics in Table 5. The summary statistics output shows that MC errors are less than $5 \%$ of the corresponding standard deviations (Sd) for all variables. It implies that the accuracy of posterior estimates in the Bayesian logistic regression is achieved. After obtaining a valid sample from the posterior distribution of the model's parameters, the next step is to infer. The posterior distribution parameters are presented in Table 5, showing the summary statistics output.

When the $95 \%$ credible set of a variable's posterior means does not contain zero, or in other words when the 95\% credible set of its odds ratio does not include one, the variable is said to be statistically significant. Gender, age, family monthly income, study hours, stimulant use throughout the study, English language competence, EGSECE score, previous attitude toward TVET, contentment by teachers, and satisfaction with department placement were significant, as indicated in Table 5 .

\section{Discussion}

This study aims to determine the factors that influence students' academic achievement at polytechnic colleges. Gender, age, family monthly income, study hours, stimulant use during the study, English language proficiency, EGSECE score, previous attitude toward TVET, teacher satisfaction, and department placement satisfaction were identified as covariates that can significantly influence TVET students' academic achievement. Note that the contribution of each covariate has been discussed by interpreting the coefficients $(\beta)$ and the odds ratio value $\left(e^{\beta}\right)$. It is worth noting that the odds ratio interpretation of a given covariate is only valid if and only if the other covariates are kept constant.

5.1. Influences of Sociodemographic Variables on Academic Achievement. Gender, age, and family monthly income significantly impacted TVET students' academic outcomes among the numerous sociodemographic factors studied. Table 5 clearly shows that male students have 2.953 times more chances of receiving a satisfactory result than female students $(\beta 2=1.083, \mathrm{OR}=2.95$, and $95 \% \mathrm{CI}$ for $\beta 2$ (1.681, 2.9535)). Male students were 2.95 times more likely than 
Table 1: Frequency distribution of sociodemographic variables.

\begin{tabular}{|c|c|c|}
\hline Independent variable & Category & Count $(\%)$ \\
\hline \multirow{2}{*}{ Gender } & Female & $238(44.4)$ \\
\hline & Male & $298(55.6)$ \\
\hline \multirow{9}{*}{ Field of study (dept.) } & Secretarial science & $59(11)$ \\
\hline & Hardware and network & $35(6.5)$ \\
\hline & Industrial electrical machine and drive & $46(8.6)$ \\
\hline & Engine service & $35(6.5)$ \\
\hline & General metal fabrication & $33(6.2)$ \\
\hline & Construction & $238(44.4)$ \\
\hline & Front office & $28(5.2)$ \\
\hline & Textile and garment & $11(2)$ \\
\hline & Small scale irrigation and derange & $51(9.5)$ \\
\hline \multirow{5}{*}{ Religion } & Orthodox & $164(30.6)$ \\
\hline & Protestant & $289(53.9)$ \\
\hline & Muslim & $29(5.4)$ \\
\hline & Catholic & $50(9.3)$ \\
\hline & Other & $4(0.7)$ \\
\hline \multirow{2}{*}{ Family residence } & Rural & $116(21.6)$ \\
\hline & Urban & $420(78.4)$ \\
\hline \multirow{2}{*}{ Living with family } & No & $266(49.6)$ \\
\hline & Yes & $270(50.4)$ \\
\hline \multirow{3}{*}{ Distance from school } & $<1 \mathrm{~km}$ & $180(33.6)$ \\
\hline & $1-3 \mathrm{~km}$ & $160(29.9)$ \\
\hline & $>3 \mathrm{~km}$ & $196(36.6)$ \\
\hline \multirow{4}{*}{ Family monthly income (ETB) } & $<750$ & $89(16.6)$ \\
\hline & $750-1500$ & $167(31.2)$ \\
\hline & $1500-3000$ & $122(22.8)$ \\
\hline & $>3000$ & $158(29.5)$ \\
\hline \multirow{3}{*}{ Family employment status } & Neither employed & $195(36.4)$ \\
\hline & Father or mother employed & $221(41.2)$ \\
\hline & Both employed & $120(22.4)$ \\
\hline \multirow{5}{*}{ The highest educational level in the family } & Illiterate & $99(18.5)$ \\
\hline & Primary comp. & $138(25.7)$ \\
\hline & Secondary comp. & $130(24.3)$ \\
\hline & Certificate or diploma & $98(18.3)$ \\
\hline & Degree or above & $71(13.2)$ \\
\hline \multirow{2}{*}{ Marital status } & Single & $488(91.0)$ \\
\hline & Married & $48(9.0)$ \\
\hline \multirow{4}{*}{ Student income (in birr) } & $<100$ & $132(24.6)$ \\
\hline & $100-300$ & $172(32.1)$ \\
\hline & $300-700$ & $133(24.8)$ \\
\hline & $>700$ & $99(18.5)$ \\
\hline \multirow{3}{*}{ Tuition fee } & Student & $69(12.9)$ \\
\hline & Family or relatives & $356(66.4)$ \\
\hline & Government & $111(20.7)$ \\
\hline
\end{tabular}

TABLE 2: Summary statistics of age and EGSECE result.

\begin{tabular}{lcccc}
\hline Independent variable & Minimum & Maximum & Mean & St. dev $( \pm)$ \\
\hline Age & 16 & 39 & 19.99 & 1.906 \\
EGSECE score & 1.71 & 3.20 & 2.1579 & 0.21075 \\
\hline
\end{tabular}

female students to achieve academic success. According to the above data, polytechnic colleges are better suitable for male students than female students. It is unsurprising in vocational colleges, given that, for many years in Ethiopia, only males were regarded for this form of education. Girls and women are still marginalized as far as TVET is concerned. A closer examination of girls' enrolment in TVET reveals a heavy traditional bias in favor of agriculture and 
TABle 3: Frequency distribution of academic variables.

\begin{tabular}{|c|c|c|}
\hline Independent variable & Category & $\begin{array}{c}\text { Count } \\
\text { (\% of } 536)\end{array}$ \\
\hline \multirow{2}{*}{ Study with friends } & No & $182(34.0)$ \\
\hline & Yes & $354(66.0)$ \\
\hline \multirow{4}{*}{ Study hour } & No study & $111(20.7)$ \\
\hline & $<1 \mathrm{hr}$ & $108(20.1)$ \\
\hline & $2-3 \mathrm{hrs}$ & $186(34.7)$ \\
\hline & $>3 \mathrm{hrs}$ & $131(24.4)$ \\
\hline \multirow{3}{*}{ Study place } & Library & $257(47.9)$ \\
\hline & Home & $173(32.3)$ \\
\hline & Garden & $106(19.8)$ \\
\hline \multirow{4}{*}{ Usage of stimulant } & Nothing & $218(40.7)$ \\
\hline & Gum & $140(26.1)$ \\
\hline & Coffee & $116(21.6)$ \\
\hline & Khat & $62(11.6)$ \\
\hline \multirow{3}{*}{ Days of absence } & No & $273(50.9)$ \\
\hline & 1-3 days & $154(28.7)$ \\
\hline & $>3$ days & $109(20.3)$ \\
\hline \multirow{3}{*}{ English proficiency } & Poor & $175(32.6)$ \\
\hline & Good & $218(40.7)$ \\
\hline & Very good & $143(26.7)$ \\
\hline \multirow{2}{*}{ Job in free time } & Yes & $205(38.2)$ \\
\hline & No & $331(61.8)$ \\
\hline \multirow{2}{*}{ Persons motivating to enroll } & Myself & $367(68.5)$ \\
\hline & Others & $169(31.5)$ \\
\hline \multirow{3}{*}{ Reason to enroll } & Lack of choice & $198(36.9)$ \\
\hline & $\begin{array}{c}\text { Easy job/low tuition } \\
\text { fee }\end{array}$ & $139(25.9)$ \\
\hline & Interest & $199(37.1)$ \\
\hline \multirow{3}{*}{$\begin{array}{l}\text { Previous awareness about } \\
\text { TVET }\end{array}$} & Low & $84(15.7)$ \\
\hline & Medium & $297(55.4)$ \\
\hline & High & $155(28.9)$ \\
\hline \multirow{2}{*}{ Attitude about TVET } & Negative & $231(43.1)$ \\
\hline & Positive & $305(56.9)$ \\
\hline \multirow{2}{*}{ Job after graduation } & No & $57(10.6)$ \\
\hline & Yes & $479(89.4)$ \\
\hline
\end{tabular}

home science, with very few in the traditionally maledominated technical areas, such as building construction, power mechanics, metalwork, and woodwork. This bias could be influencing the enrolment and academic success of women in TVET programs. Previous researches by $[27,28]$ concluded with the same finding. On the other hand, [29] were found contradictory results.

The current study discovered that TVET students' academic achievements were inversely correlated with their age $(\beta 3=-0.1739, \mathrm{OR}=0.84$, and $95 \% \mathrm{CI}$ for $\beta 3(-0.04,0.84))$. The study found that older students were $16 \%$ less likely to succeed academically than students aging a year younger. As a result, younger students in TVET colleges have an advantage, and they are more likely to become academically competent than older students. It is supported by [27] in her study on factors affecting university (Grade Point Average) GPA of Maryland Community College transfer students.

Family monthly income was another sociodemographic variable that predicted academic achievement in this study. According to Bayesian logistic regression analysis findings,
TABle 4: Descriptive statistics of students' overall satisfaction variables.

\begin{tabular}{|c|c|c|}
\hline Independent variable & Category & $\begin{array}{c}\text { Count } \\
\text { (\% of } 536)\end{array}$ \\
\hline \multirow{5}{*}{ Satisfaction with library service } & Very low & $67(12.5)$ \\
\hline & Low & $87(16.2)$ \\
\hline & Medium & $39(7.3)$ \\
\hline & High & $159(29.7)$ \\
\hline & Very high & $184(34.3)$ \\
\hline \multirow{5}{*}{ Satisfaction with teaching facilities } & Very low & $77(14.4)$ \\
\hline & Low & $128(23.9)$ \\
\hline & Medium & $54(10.1)$ \\
\hline & High & $152(28.4)$ \\
\hline & Very high & $125(23.3)$ \\
\hline \multirow{5}{*}{ Satisfaction with teaching method } & Very low & $61(11.4)$ \\
\hline & Low & $82(15.3)$ \\
\hline & Medium & $59(11.0)$ \\
\hline & High & $175(32.6)$ \\
\hline & Very high & $159(29.7)$ \\
\hline \multirow{5}{*}{ Satisfaction with teachers } & Very low & $44(8.2)$ \\
\hline & Low & $58(10.8)$ \\
\hline & Medium & $47(8.8)$ \\
\hline & High & $172(32.1)$ \\
\hline & Very high & $215(40.1)$ \\
\hline \multirow{5}{*}{ Satisfaction with class environment } & Very low & $69(12.9)$ \\
\hline & Low & $113(21.1)$ \\
\hline & Medium & $75(14.0)$ \\
\hline & High & $131(24.4)$ \\
\hline & Very high & $148(27.6)$ \\
\hline \multirow{5}{*}{ Satisfaction with college reputation } & Very low & $72(13.4)$ \\
\hline & Low & $75(14.0)$ \\
\hline & Medium & $57(10.6)$ \\
\hline & High & $139(25.9)$ \\
\hline & Very high & $193(36.0)$ \\
\hline \multirow{5}{*}{ Satisfaction with department placement } & Very low & $108(20.1)$ \\
\hline & Low & $89(16.6)$ \\
\hline & Medium & $115(21.5)$ \\
\hline & High & $120(22.4)$ \\
\hline & Very high & $104(19.4)$ \\
\hline
\end{tabular}

students from high-income families are more likely to achieve academically than low-income families. It is supported by [30], the research entitled "Factors Affecting Students' Performance: A Case of Private Colleges." As a result of the initial findings, it appears that students from low-income families require substantial financial assistance.

5.2. Influences of School-Related Factors on Academic Achievement. According to the findings of this study, study hours are strongly linked to TVET students' academic success. In the current study, study hour is grouped into four categories, i.e., no study, $<1$ hour, 2-3 hours, and $>3$ hours. In the analysis, the reference category was not studied at all. Only the last category, i.e., $>3$ hours, was found significant $(\beta 17=1.1, \mathrm{OR}=3$, and $95 \% \mathrm{CI}$ for $\beta 17(0.24,1.97))$. As a result, according to the current study, students who study for more than 3 hours per day are three times more likely to be academically competent than students who do not study at all. This finding is also supported by [30]. As a result, 
TABLE 5: Summary statistics for significant covariates in the Bayesian logistic model.

\begin{tabular}{|c|c|c|c|c|c|c|}
\hline \multirow{2}{*}{ Nodes } & \multirow{2}{*}{ Mean $(\beta)$} & \multirow{2}{*}{ Sd } & \multirow{2}{*}{ Mc error } & \multicolumn{2}{|c|}{$95.0 \% \mathrm{CI}$ for mean $(\beta)$} & \multirow{2}{*}{$\operatorname{OR}\left(e^{\beta}\right)$} \\
\hline & & & & Lower & Upper & \\
\hline Alpha $\left(\beta_{1}\right)$ & -3.09 & 1.2034 & 0.07616 & -6.766 & 0.4397 & 0.0455 \\
\hline Gender (1) $(\beta 2)$ & 1.083 & 0.2496 & 0.002366 & 0.5117 & 1.681 & 2.9535 \\
\hline Age $\left(\beta_{3}\right)$ & -0.1739 & 0.0621 & 0.002257 & -0.3011 & -0.03931 & 0.8403 \\
\hline \multicolumn{7}{|c|}{ Family monthly income (FMI) } \\
\hline FMI $(1)\left(\beta_{5}\right)$ & 1.09 & 0.3652 & 0.003579 & 0.2596 & 1.924 & 2.9742 \\
\hline FMI $(2)\left(\beta_{6}\right)$ & 1.235 & 0.3933 & 0.003761 & 0.364 & 2.12 & 3.4383 \\
\hline FMI $(3)\left(\beta_{7}\right)$ & 1.546 & 0.3821 & 0.003686 & 0.7221 & 2.391 & 4.6926 \\
\hline \multicolumn{7}{|c|}{ Study hour (SH) } \\
\hline $\mathrm{SH}(1)\left(\beta_{15}\right)$ & 0.5826 & 0.3962 & 0.003344 & -0.08787 & 1.264 & 1.7906 \\
\hline $\mathrm{SH}(2)\left(\beta_{16}\right)$ & 0.5556 & 0.3201 & 0.002956 & -0.1781 & 1.307 & 1.7429 \\
\hline $\mathrm{SH}(3)\left(\beta_{17}\right)$ & 1.101 & 0.3487 & 0.002917 & 0.2417 & 1.972 & 3.0071 \\
\hline \multicolumn{7}{|c|}{ Usage of stimulant (TS) } \\
\hline TS $(1)\left(\beta_{18}\right)$ & -2.919 & 0.3874 & 0.003658 & -3.624 & -2.239 & 0.0539 \\
\hline TS $(2)\left(\beta_{19}\right)$ & -2.877 & 0.3992 & 0.003564 & -3.714 & -2.06 & 0.0563 \\
\hline TS (3) $\left(\beta_{20}\right)$ & -4.044 & 0.4524 & 0.004002 & -5.211 & -2.974 & 0.017527 \\
\hline \multicolumn{7}{|c|}{ English proficiency (EP) } \\
\hline $\operatorname{EP}(1)\left(\beta_{23}\right)$ & 0.8704 & 0.3211 & 0.003135 & 0.1296 & 1.629 & 2.3878 \\
\hline $\operatorname{EP}(2)\left(\beta_{24}\right)$ & 1.328 & 0.3021 & 0.002353 & 0.6559 & 2.02 & 3.7734 \\
\hline EGSECE score $\left(\beta_{25}\right)$ & 1.849 & 0.5871 & 0.01502 & 0.5233 & 3.125 & 6.3534 \\
\hline Previous TVET Attitude (PTA) $\left(\beta_{28}\right)$ & 0.5246 & 0.2649 & 0.00203 & 0.09542 & 1.132 & 1.689783 \\
\hline \multicolumn{7}{|c|}{ Satisfaction with teachers (SBT) } \\
\hline $\operatorname{SBT}(1)\left(\beta_{33}\right)$ & 0.3182 & 0.5201 & 0.004258 & -0.8846 & 1.517 & 1.3746 \\
\hline $\operatorname{SBT}(2)\left(\beta_{34}\right)$ & 1.272 & 0.5321 & 0.004697 & 0.06755 & 2.478 & 3.5679 \\
\hline $\operatorname{SBT}(3)\left(\beta_{35}\right)$ & 1.346 & 0.3992 & 0.003946 & 0.3469 & 2.329 & 3.8420 \\
\hline $\operatorname{SBT}(4)\left(\beta_{36}\right)$ & 1.121 & 0.4218 & 0.00441 & 0.1086 & 2.12 & 3.0679 \\
\hline \multicolumn{7}{|c|}{ Satisfaction with department placement (SBDP) } \\
\hline $\operatorname{SBDP}(1)\left(\beta_{37}\right)$ & 0.9258 & 0.4187 & 0.003082 & 0.1026 & 2.163 & 3.067921 \\
\hline $\operatorname{SBDP}(2)\left(\beta_{38}\right)$ & 1.127 & 0.3921 & 0.003346 & 0.2228 & 2.036 & 3.0863 \\
\hline $\operatorname{SBDP}(3)\left(\beta_{39}\right)$ & 0.7933 & 0.3824 & 0.003051 & 0.1069 & 1.9 & 2.697971 \\
\hline $\operatorname{SBDP}(4)\left(\beta_{40}\right)$ & 1.034 & 0.4158 & 0.003549 & 0.1086 & 1.979 & 2.8122 \\
\hline
\end{tabular}

students must be dedicated to their studies and devote more time to achieving academic success. Furthermore, parents, instructors, and management should work together to establish an environment that encourages students to study hard and concentrate on their studies.

The use of stimulants during study time is another covariate that significantly impacts TVET students' academic outcomes. Students who do not use stimulants are included in the reference group. The study found that students who chew gum or Khat or drink coffee as a stimulant during study time have at least $94 \%$ lower chance of being academically successful than students in the control group $[(\beta 18=-2.92, \mathrm{OR}=0.053$, and $95 \% \mathrm{CI}$ for $\beta 18(-3.62$, $-2.23)),(\beta 19=-2.87, \mathrm{OR}=0.056$, and $95 \% \mathrm{CI}$ for $\beta 19$ $(-3.71,-2.06))$, and $(\beta 20=-4.04, \mathrm{OR}=0.017$, and $95 \% \mathrm{CI}$ for $\beta 20(-5.21,-2.97))]$. Unlike most of the relevant factors examined in this study, stimulant use had a detrimental impact on TVET students' academic achievement. As a result, students must avoid using any stimulants while studying.

English language proficiency is also a strong predictor of academic achievement in this study. It has been divided into three categories: poor, good, and very good. Students who have a good command of the English language have a 2.3 times greater likelihood of being academically competent than students who have a poor command of the language (i.e., $\beta 23=0.87, \mathrm{OR}=2.38$, and 95\% CI for $\beta 23(0.13,1.63)$ ). Students who are very good at proficiency are also 3.7 times more likely than students in the reference category to succeed (i.e., $\beta 24=1.33, \mathrm{OR}=3.77$, and $95 \% \mathrm{CI}$ for $\beta 23(0.65$, 2.02)). Understandably, polytechnic colleges use English as their primary teaching medium. As a result, a poor command of the English language is linked to poor academic performance. Previous researches are done by $[29,31]$ who also concluded with the same findings.

The EGSECE score of students is another important predictor of TVET students' academic achievement (i.e., $\beta 25=1.85, \mathrm{OR}=6.35$, and $95 \% \mathrm{CI}$ for $\beta 23(0.52,3.12)$ ). The odds ratio associated with this covariate, 6.35 , indicates that students with a 1-point higher EGSECE score are 6.36 times more likely to be academically competent. The current study's findings revealed that high EGSECE score values were linked to strong academic performance. As a result, students with a good academic foundation in polytechnic colleges were more likely to be academically competent. Therefore, enhancing the quality of high school education strongly impacts students' academic success at polytechnic colleges. It is supported by [31] in her study on "factors contributing to academic achievements of students in private universities in Kenya."

Another factor influencing TVET students' academic competency is their previous attitude toward TVET 
$(\beta 28=0.52$, OR 1.68 , and $95 \%$ CI for $\beta 28(0.09,1.13))$. This covariate's odds ratio reveals that students who have previously had a positive attitude toward TVET are 1.68 times more likely to have an acceptable result than students who have not. In Ethiopia, TVET is seen as only suitable for those with limited academic abilities. Furthermore, students who enroll in vocational school find it difficult, if not impossible, to continue their studies. The poor pay earned by vocationally trained graduates aggravates the situation even more. Students taking TVET topics have reported low morale and a negative attitude due to this. This mindset could have hindered the proper implementation of technical and vocational programs and students' academic achievement.

The study also found that students' teacher satisfaction significantly impacted academic performance. It has five categories (i.e., very low, low, medium, high, and very high), and the first category has been taken as a reference. However, the category "low" was not found significant. Students with a medium level of teacher satisfaction are 3.56 times more likely to be academically competent than students in the reference group $\left(\beta_{34}=0.1 .27, \mathrm{OR}=3.56\right.$, and $95 \% \mathrm{CI}$ for $\beta 34(0.06,2.47))$. Similarly, students with a high teacher satisfaction level are 3.842 times more likely to obtain a satisfactory grade than students in the reference group $(\beta 35=1.34, \mathrm{OR}=3.84$, and $95 \% \mathrm{CI}$ for $\beta 35(0.34,2.33))$. Finally, students with very high teacher satisfaction are 3.067 times more likely than the reference group to be academically competent $\left(\beta 36=0.52\right.$, OR 1.68 , and $95^{\%} \mathrm{CI}$ for $\beta 36$ $(0.09,1.13))$. As a result, it may be inferred that instructor satisfaction was associated with student achievement in polytechnic colleges. Therefore, teachers' professional development should be adequately supported by conferences, seminars, workshops, and pre- and in-service training programs.

Student satisfaction with training sector was the final variable evaluated relevant in this study (department). For this covariate, all category coefficients were determined to be significant. As demonstrated in Table 5, students who reported low, medium, high, or very high satisfaction with their training sector were 2.6 times more likely than students in the reference category to be academically competent. Students who are happy with their department are more likely to receive good grades. The impact of department placement satisfaction on academic success was addressed in a study conducted by $[14,28]$.

\section{Conclusions and Implications}

The present study aimed to identify the significant factors that determine the academic achievements of TVET students. The study results have shown that gender, family monthly income, study hour, usage of stimulants, English proficiency, EGSECE score, previous attitude toward TVET, and satisfaction with department placement are potential factors that significantly determine the academic achievements of TVET students. In addition, it is found that age and usage of stimulants were negatively associated with academic achievement; on the other hand, male gender, family monthly income, study hour, English proficiency, EGSECE score, previous attitude toward TVET, satisfaction with teachers, and satisfaction with department placement were positively associated with academic achievement. Generally, this study shows that female gender, low family income, studying for less amount of time, using stimulants during the study, having low English language proficiency, having low EGSECE result, negative perception toward TVET, and low satisfaction with training sector (department) are associated with less academic competency in Bahir Dar Polytechnic College.

Based on the findings of the current study, the author would like to forward the following suggestions:

(i) Exceptional support and encouragement should be given to female TVET students to make them competitive with their male counterparts.

(ii) It would be better for students to spend more learning hours and take fewer stimulants during the study. Besides, student families and teachers should support and encourage students to give more attention to their studies.

(iii) TVET curriculum should be revised as it contains those courses which are helping students to develop their English language skills. In addition, continuous capacity-building training should be delivered for teachers in TVET.

(iv) The concerned body must promote a good image of vocational education and its students to society through various techniques like media.

(v) Finally, rather than imposing constraints and limits (in terms of student accomplishment) on students' freedom of choice of training sector or department, their preferences should be honored to the greatest extent possible. Because TVET is more practical than general education, students who are uninterested in their chosen field of study are unlikely to succeed academically.

The current study has various implications for understanding the significant factors influencing students' success and improving students' academic achievement at polytechnic colleges. The following are some of the implications of the findings of this study:

(i) The finding of this research may be an input for stakeholders, i.e., TVET teachers, administration bodies of TVET institutions, policymakers, etc., to review and include these results appropriately to improve students' interest and academic success.

(ii) The findings of this study would also provide valuable information for other researchers and further studies in TVET.

\section{Limitation of the Study}

The absence of previous studies on TVET education in the research area was a fundamental limitation of the current study. Furthermore, the scope of the study was restricted to 
public TVET polytechnic colleges. As a result, a substantial number of high-quality research papers are expected in this domain. In the future, the author would like to conduct a study on a variety of aspects of TVET from both the public and the private sectors.

\section{Data Availability}

The data that support the findings of this study are available from the corresponding author upon a reasonable request.

\section{Conflicts of Interest}

The author declares no conflicts of interest.

\section{Acknowledgments}

The author would like to acknowledge the Bahir Dar Polytechnic College Dean's Office and Registrar's Office for their complete and sincere assistance in providing relevant secondary information. Thanks are also due to the respondents (students) who contributed to the study by willingly responding to the questionnaire.

\section{References}

[1] United Nations Educational, S. and C. Organization, Revised Recommendation Concerning Technical and Vocational education, 2001, to Be Adopted by the General Conference of UNESCO at its Thirty-First Session, United Nations Educational, Paris, France, 2001.

[2] Education M. O. S. A. H, Ethiopian Technical and Vocational Education and Training Policy and Strategy, Education, M. O. S. A. H, Addis Ababa, Ethiopia, 2020.

[3] Training, U.-U. I. C. f. T. a.V. E. a. Bonn declaration. 2004 https://unevoc.unesco.org/home/ Bonn+Declaration\&context $=$.

[4] K. Abraham, Ethiopia: The Challenge of 20th Century Education and Modernisation, and the Role of Swedish Aid, Swedish International Development Authority (SIDA), Stockholm, Sweden, 1992.

[5] A. Union, "Strategy to revitalize technical and vocational education and training (TVET) in Africa," in Proceedings of the Bureau of the Conference of Ministers of Education of the African Union (COMEDAF II+), Johannesburg, South Africa, August 2007.

[6] Education, M. o., "National technical \& vocational education and training strategy. Engineering Capacity Building Program (EBCP)," 2008.

[7] P. Krishnan and I. Shaorshadze, Technical and Vocational Education and Training in Ethiopia, International Growth Centre, London School of Economics and Political Science, London, UK, 2013.

[8] A. Biazen and A. Abegaz, Technical Vocational Education and Training in Ethiopia Mapping: Learn4Work-Schokland Programme on TVET, Edukans Foundation, Addis Ababa, Ethiopia, 2009.

[9] R. Crosnoe, M. K. Johnson, and G. H. Elder Jr, "School size and the interpersonal side of education: an examination of race/ethnicity and organizational context," Social Science Quarterly, vol. 85, no. 5, pp. 1259-1274, 2004.

[10] M. S. Farooq, A. H. Chaudhry, M. Shafiq, and G. Berhanu, "Factors affecting students' quality of academic performance: a case of secondary school level," Journal of Quality and Technology Management, vol. 7, no. 2, pp. 1-14, 2011.

[11] P. Smith, "Building a world of learning for all," Prospects, vol. 36, no. 1, pp. 5-7, 2006.

[12] W. Bauer, "TVET teachers and instructors in Germany," in International Perspectives on Teachers and Lecturers in Technical and Vocational Education, P. Grollman and F. Ranuer, Eds., Springer, Dordrecht, The Netherlands, pp. 123-158, 2007.

[13] E. B.-D. Aryeetey, D. Doh, and P. Andoh, "From prejudice to prestige: vocational education and training in Ghana," 2011.

[14] O. Q. Essel, E. Agyarkoh, S. Mohammed, and P. D. Yankson, "TVET stigmatization in developing countries: reality or fallacy," European Journal of Training and Development Studies, vol. 1, no. 1, pp. 27-42, 2014.

[15] O. O. Kennedy, "Philosophical and sociological overview of vocational-technical education in Nigeria," International Journal of Academic Research in Business and Social Sciences, vol. 1, p. 167, 2011.

[16] J. Smith and R. Naylor, "Determinants of degree performance in UK universities: a statistical analysis of the 1993 student cohort," Oxford Bulletin of Economics and Statistics, vol. 63, no. 1, pp. 29-60, 2001.

[17] J. Ermisch and M. Francesconi, "Family matters: impacts of family background on educational attainments," Economica, vol. 68 , no. 270 , pp. 137-156, 2001.

[18] A. Agus and Z. K. Bin Mohamed Makhbul, "An empirical study on academic achievement of business students pursuing higher education: An emphasis on the influence of family backgrounds. A new paradigm of borderless education: challenges, strategies, and implications for effective education through localization and," vol. 168, 2002.

[19] D. R. Marburger, "Absenteeism and undergraduate exam performance," The Journal of Economic Education, vol. 32, no. 2, pp. 99-109, 2001.

[20] E. A. Hanushek, J. F. Kain, J. M. Markman, and S. G. Rivkin, "Does peer ability affect student achievement?" Journal of Applied Econometrics, vol. 18, no. 5, pp. 527-544, 2003.

[21] G. R. Goethals, "Peer effects, gender, and intellectual performance among students at a highly selective college: a social comparison of abilities analysis," 2001.

[22] N. A. Gonzales, A. M. Cauce, R. J. Friedman, and C. A. Mason, "family, peer, and neighborhood influences on academic achievement among African-American adolescents: one-year prospective effects," American Journal of Community Psychology, vol. 24, no. 3, pp. 365-387, 1996.

[23] A. Gelman, J. B. Carlin, H. S. Stern, D. B. Dunson, and A. Vehtari, Bayesian Data Analysis, Chapman and Hall/CRC, Boca Raton, FL, USA, 1995.

[24] I. Ntzoufras, Bayesian Modeling Using WinBUGS, Vol. 698, John Wiley \& Sons, Hoboken, NJ, USA, 2011.

[25] J. Albert, Bayesian Computation with R, Springer Science \& Business Media, Berlin, Germany, 2009.

[26] B. Walsh, "Introduction to Bayesian analysis," 2002.

[27] S. E. Hall, Factors Affecting University GPA of Maryland Community College Transfer Students Who Persist to Graduation, University of Maryland, College Park, MD, USA, 2005.

[28] J. Cheesman, N. Simpson, and A. G. Wint, "Determinants of student performance at university: reflections from the Caribbean," 2006 
[29] N. Harb and A. El-Shaarawi, "Factors affecting students' performance United Arab Emirates University," p. 11, 2006.

[30] S. Naqvi, "Factors affecting students' performance a case of private colleges," Bangladesh E-Journal of Sociology, vol. 3, 2006.

[31] F. K. Karimi, Factors Contributing to the Academic Performance of Students in a Private University in Kenya, University of South Africa, Pretoria, South Africa, 2008. 